\title{
Maximum covariance analysis to identify intraseasonal oscillations over tropical Brazil
}

\author{
Naurinete J. C. Barreto ${ }^{1}$ Michel d. S. Mesquita ${ }^{2} \cdot$ David Mendes $^{1}$. \\ Maria H. C. Spyrides ${ }^{1} \cdot$ George U. Pedra $^{1} \cdot$ Paulo S. Lucio $^{1}$
}

Received: 18 March 2016 / Accepted: 11 October 2016 / Published online: 21 October 2016

(C) The Author(s) 2016. This article is published with open access at Springerlink.com

\begin{abstract}
A reliable prognosis of extreme precipitation events in the tropics is arguably challenging to obtain due to the interaction of meteorological systems at various time scales. A pivotal component of the global climate variability is the so-called intraseasonal oscillations, phenomena that occur between 20 and 100 days. The Madden-Julian Oscillation (MJO), which is directly related to the modulation of convective precipitation in the equatorial belt, is considered the primary oscillation in the tropical region. The aim of this study is to diagnose the connection between the MJO signal and the regional intraseasonal rainfall variability over tropical Brazil. This is achieved through the development of an index called Multivariate Intraseasonal Index for Tropical Brazil (MITB). This index is based on Maximum Covariance Analysis (MCA) applied to the filtered daily anomalies of rainfall data over tropical Brazil against a group of covariates consisting of: outgoing longwave radiation and the zonal component $\mathbf{u}$ of the wind at 850 and $200 \mathrm{hPa}$. The first two MCA modes, which were used to create the $M I T B_{1}$ and $M I T B_{2}$ indices, represent 65 and $16 \%$ of the explained variance, respectively. The combined multivariate index was able to satisfactorily represent the pattern of intraseasonal variability over tropical Brazil, showing that there are periods of activation and inhibition of precipitation connected with the pattern of MJO propagation. The MITB index could potentially be used as a diagnostic tool for intraseasonal forecasting.
\end{abstract}

Naurinete J. C. Barreto

netebarreto@gmail.com

1 Universidade Federal do Rio Grande do Norte, Natal, RN, Brazil

2 Uni Research Climate, Bjerknes Centre for Climate Research, Bergen, Norway
Keywords Tropical climate $\cdot$ Madden-Julian Oscillation · Maximum Covariance Analysis · MITB index

\section{Introduction}

The low frequency climate variability observed in various parts of the globe is the result of the interaction of various atmospheric systems (Barnett 1991). Intraseasonal fluctuations are one of the most important ones, because they influence the convective activity, precipitation patterns, the occurrence of hurricanes in the Gulf of Mexico (Maloney and Hartmann 2000), South American monsoon systems (Jones and Carvalho 2002), atmospheric blocking in maritime continent (Inness and Slingo 2006), among others. Moreover, the low frequency variability, usually defined as covering periods between 20-100 days, exhibit considerable complexity both in time and in space, and one has to resort to the use of complex techniques to detect these events in real-time (Alvarez et al. 2014; Alves et al. 2012; Vitorino et al. 2006). For the South American region, the Madden-Julian Oscillation (MJO) is an intraseasonal low frequency system of major relevance, due to its relationship to weather extremes and intraseasonal climate variability (Jones et al. 2004), and yet detailed knowledge of its influence in South American climate is still quite incomplete (Alvarez et al. 2015).

Thus, a more detailed description of the MJO influence on South American rainfall, temperature, and circulation of the atmosphere and their seasonal variations, would provide a fundamental basis for the monitoring of MJO impacts in this region (Alvarez et al. 2015). A number of regionalized studies on tropical South America were conducted, in which they: (a) identified the intraseasonal signal, especially in the rainy season (January to May) 
(Liebmann et al. 2004; Jones et al. 2004; De Souza and Ambrizzi 2006; Muza et al. 2009; Alves et al. 2012), b) found dynamic links between the South Atlantic Convergence Zone (SACZ) and the MJO (Grimm and Silva Dias 1995; Paegle et al. 2000; Todd et al. 2003; Grimm and Zilli 2009; Kodama et al. 2012; Gonzalez and Vera 2013), and c) found evidence of an increased frequency of precipitation extremes related to active MJO events (Jones et al. 2004; Carvalho et al. 2005). In spite of the large amount of studies on South American intraseasonal variability, an efficient intraseasonal prognosis is still a challenge due to the spatio-temporal characteristic of atmospheric interactions that modulate the variation in precipitation at the intraseasonal scale, especially related to extremes in the tropical region.

In short, the MJO is characterized by a global zonal wave with wave numbers between 1 and 3 and eastward propagation having periods between 30 and 90 days. This oscillation has a strong seasonal signal with greater intensity during the austral summer and fall seasons, which favours the development of the rainy season in tropical Brazil (Madden and Julian 1971, 1972; Weickmann 1983; Knutson and Weickmann 1987; Hendon and Salby 1994; Wu et al. 1999; Madden and Julian 1994; Zhang and Dong 2004; Maloney and Hartmann 2001). The modulations in the aforementioned rainfall season occur through the establishment of a deep quasi-stationary convective band, which is triggered by the simultaneous expression of the South Atlantic Convergence Zone (SACZ) and the Intertropical Convergence Zone (ITCZ). Such regional mechanisms are dynamically linked with the northward propagation of precipitation anomalies during the MJO displacement over South America and the tropical Atlantic Ocean (De Souza and Ambrizzi 2006; Muza et al. 2009; Valadão et al. 2015).

Moreover, there is an interaction between the intraseasonal signals (mainly the MJO signal), and other oceanic and atmospheric events that happen at different scales in the tropics. For example, at the interannual timescale, the intraseasonal signal may interact with the El NiñoSouthern Oscillation and the Atlantic Dipole (Kayano and Kousky 2006; Robledo et al. 2013; Carvalho et al. 2004). At the interdecadal scale, the Pacific Decadal Oscillation and the Atlantic Multidecadal Oscillation may interact with the intraseasonal signal (Garreaud and Aceituno 2001; Wu et al. 1999). These interactions may modulate the precipitation patterns in distinct sectors of the tropical belt differently. So, the modulation of the intraseasonal signal with other scales illustrates the importance of studying the intraseasonal variability regionally. Thus, the main objective of this research work is to create an index that can capture the intraseasonal signal in the tropical region of Brazil.

Recently, several studies have been conducted to diagnose the intraseasonal variability. One of the first studies addressing the development of a multivariate index to characterize this variability, focusing mainly on the MJO, was carried out by Mathews (2000), who used the Empirical Orthogonal Function (EOF) applied to the gridded outgoing longwave radiation (OLR) data centered at the equator. The principal components (PC) resulting from the EOF analysis were considered representative in space and time; and through a vectorial projection, it was then possible to analyse the propagation of MJO-related convection in phase and space. Then, Wheeler and Hendon (2004) used the concept of vectorization, applying the EOF to a dataset composed of the equatorial average $\left(15^{\circ} \mathrm{S}-15^{\circ} \mathrm{N}\right)$ of: OLR, and the zonal component of the horizontal wind at 850 (U850) and at $200 \mathrm{hPa}$ (U200). They found that the PC index based on unfiltered data, which they called the RMM index (i.e.: Real-Time Multivariate MJO index), was able to capture fluctuations related to the MJO and the seasonal variability. Later, Ventrice et al. (2013) modified the index proposed by Wheeler and Hendon (2004), where they substituted OLR with potential velocity at $200 \mathrm{hPa}$. Overall, these (and other) studies evaluated the intraseasonal variability by looking at the global (Jones and Carvalho 2009; Maharaj and Wheeler 2005; Mathews 2000; Ventrice et al. 2013) or continental scale (Silva and Carvalho 2007), without considering specific regions, such as over tropical Brazil. Although EOF-based approaches capture the intraseasonal variability at a global scale, they may not capture extreme events at a regional scale. Also, these studies used indices that either considered the MJO or other processes separately, but that did not consider them together.

Hence, the use of a multivariate index has proven to be an efficient way to characterize the intraseasonal climate variability. Considering the potential value these multivariate indices have to capture and reproduce the intraseasonal variability dynamics, this study proposes to replace the multivariate EOF-type approach used in previous studies by the Maximum Covariance Analysis (MCA, hereafter) to characterize the intraseasonal signal. The MCA-based approach makes use of dynamic variables, (OLR, $\mathbf{u}$ component of the wind at $850 \mathrm{hPa}$ and $200 \mathrm{hPa}$ levels) with rainfall in tropical Brazil. Note that a combined EOF approach could have been used here to isolate the regional intraseasonal variability over Brazil. However, (Navarra and Simoncini 2010, p. 94) highlights the following: "the main weakness of the combined EOF: by mixing the autocovariance of each field and the cross-covariance of one field with the other, combined EOF cannot separate the patterns for the different kind of variability and one cannot tell the respective amount due to the autocovariance or to the cross-covariance. The Combined EOF mode will bear the imprint of both sectors of variability of a particular variable." In the present work, the aim is to capture the local changes in precipitation in $\mathrm{TBr}$ as a response to the dynamic variables (OLR, U850, and U200); so, one of these sets of variables could have an 
internal signal (autocovariance) that is more intense compared with the external signal (cross-covariance), such that the combined EOF would not distinguish between these signals and it would represent the stronger one.

Thus, we have opted for an alternative approach, which uses the Maximum Covariance Analysis to study the relationship between the local precipitation in $\mathrm{TBr}$ and the dynamic variables. In doing so, this research work will answer the following scientific questions with respect to the Multivariate Intraseasonal Index for Tropical Brazil (MITB) index proposed here:

(a) Does the combination of dynamic variables with precipitation improve the representation of the intraseasonal signal?

(b) Can the MITB index reasonably capture and characterize climate extremes, such as drought and heavy precipitation?

The structure of this paper is as follows. Section 2 describes the data and methods used to construct the MITB index. Then Sect. 3 is divided into three parts to: (a) study the basic characteristics of the MITB index; (b) conduct a sensitivity analysis of the MITB index to address the first scientific question; and (c) evaluate climate extremes to address the second scientific question. The summary and main conclusions are presented in Sect. 4.

\section{Datasets and statistical model}

\subsection{Datasets}

The intraseasonal variability patterns were identified using rainfall data based on daily totals from the Climate Prediction Center unified gauge (CPC) for the period from January 1979 to December 2013, obtained from their website at http://www.cpc.ncep.noaa.gov/. The CPC uses an optimized interpolation technique, which projects stationbased precipitation data onto a horizontal grid at $0.5^{\circ} \times 0.5^{\circ}$ horizontal resolution (Chen et al. 2008). The evaluation of convective activity was performed using daily OLR data based on the Advanced Very High Resolution Radiometer (AVHRR) radiation detection imager, using a horizontal resolution of $2.5^{\circ} \times 2.5^{\circ}$, available from the National Oceanic and Atmospheric Administration (NOAA) (Liebmann and Smith 1996). Also, the 850 and $200 \mathrm{hPa} \mathbf{u}$ and $\mathbf{v}$ wind data were obtained from the National Center for Environmental Prediction (NCEP)/National Center for Atmospheric Research (NCAR) Reanalysis, with spatial resolution of $2.5^{\circ} \times 2.5^{\circ}$ (Kalnay et al. 1996). These are available on their website at http://www.esrl.noaa.gov/psd/data/.

\subsection{Defining the multivariate index}

The intraseasonal signal was isolated in the raw data by applying a bandpass Lanczos filter in order to retain the low-frequency variations (Duchon 1979). The Lanczos filter uses a Fourier transform, so that the amplitudes of a time series are changed by weight functions, creating time series filtered to the desired frequency (De Souza and Ambrizzi 2006).

Here, the intraseasonal signal is defined using the Lanczos filter with 201 weights and cut-off frequencies at 20 and 100 days in the period from January 1979 to December 2013. Then, the resulting time series covered the period from April 1979 to September 2013.

\subsubsection{Maximum covariance analysis}

The MCA approach has been chosen because it is able to capture patterns of maximum covariance between two datasets; it has been found to reasonably capture atmospheric and oceanic processes (Wilks 2015). It is a robust method to investigate dominant modes of interaction, because it favors a better understanding of the relationship between groups of variables (Frankignoul et al. 2011). It consists of constructing a covariance matrix between two datasets and then performing the Singular Value Decomposition (SVD) of the resulting matrix (Levine et al. 2013). To define SVD, let $\mathbf{X}$ be a $p \times n$ matrix, where $p$ represents a group of standardized variables and $n$ time steps; $\mathbf{Y}$ is a $q \times n$ matrix, where $q$ represents another set of standardized variables. $n$ is the same for $\mathbf{X}$ and $\mathbf{Y}$, whereas $p$ and $q$ may have different sizes. Thus, the SVD covariance matrix $(\mathbf{C})$ between $\mathbf{X}$ and $\mathbf{Y}$ is represented by:

$\mathbf{C}=\frac{1}{n} \mathbf{X} \mathbf{Y}^{T}=\mathbf{U} \Lambda_{c} \mathbf{V}^{T}$

where $T$ represents the transpose of a matrix, $\Lambda$ is an $r \times r$ diagonal matrix, where its non-negative singular values $\lambda(i=1, \ldots, r)$ are arranged in descending order, with $r \leq \min (p, q, n-1)$. SVD outputs the $p \times r$ matrix $\mathbf{U}$ and the $q \times r$ matrix $\mathbf{V}$, which represent the singular vectors of the spatial pattern. The first pair of singular vectors, i.e. $\left(\mathbf{U}_{1}, \mathbf{V}_{1}\right)$, describes the largest fraction of the quadratic covariance, while successive pairs describe a maximum fraction of quadratic covariance not explained by the previous pairs.

Next, let the $n \times r$ matrices $\mathbf{A}$ and $\mathbf{B}$ represent the temporal expansion coefficients, which satisfy the following equations:

$\mathbf{X}=\mathbf{U A}^{T} \quad \mathbf{Y}=\mathbf{V B}^{T}$ 
Then from Eq. 2, one may obtain the following relationships:

$$
\mathbf{A}=\mathbf{X}^{T} \mathbf{U} \quad \mathbf{B}=\mathbf{Y}^{T} \mathbf{V}
$$

The columns of the matrices $\mathbf{A}$ and $\mathbf{B}$ are time series, which characterize each variability mode. Note that since $\mathbf{X}$ and $\mathbf{Y}$ are here defined as two standardized fields, the MCA response is not very different from the Canonical Correlation Analysis (CCA) approach. The only difference is that the MCA singular vectors are orthonormal to each other and the expansion coefficients are uncorrelated (Mo 2003).

Here, the MCA results are assessed through the square fraction of covariance (SFC), defined as:

$$
S C F_{k}=\frac{\lambda_{k}^{2}}{\sum \lambda_{i}^{2}}
$$

where $k$ represents the MCA mode (i.e. $k=1, \ldots, r$ ).

In this study, the matrices $\mathbf{X}$ and $\mathbf{Y}$ respectively refer to the following set of variables: a) the spatial precipitation over tropical Brazil ('TBr', hereafter), such that $\mathbf{X}=p_{i, j}$ where $\{-85<i<=-34 ;-19<j<=4 \mid i, j \in Z\}$. $i$ and $j$ represent the longitude and latitude, respectively; and b) the meridional average from $15^{\circ} \mathrm{S}-15^{\circ} \mathrm{N}$ of OLR, U850 and $\mathrm{U} 200$, so that $\mathbf{Y}=\left(\begin{array}{lll}O L R_{i} & U 850_{i} & U 200_{i}\end{array}\right)^{T}$, where $\{-180<=i<=180 \mid i \in Z\}$. Also, $\mathbf{u}_{k}$ is the coefficient related to the precipitation for mode $k ; \mathbf{v}_{k}$ is the coefficient related the equatorial for mode $k ; \mathbf{a}_{k}$ and $\mathbf{b}_{k}$ are the temporal expansion coefficients related to precipitation and equatorial average, respectively.

Simply put, $\mathbf{Y}$ is a single matrix composed of three variables: OLR, U850, and U200, such that there are 432 time series for $\mathbf{Y}$ (i.e.: 144 times three variables). $\mathbf{X}$ corresponds to a matrix composed of the precipitation variable only. So, the MCA will return the relationship between the dynamic component $(\mathbf{Y})$ and the precipitation variable $(\mathbf{X})$. These two sets of variables, i.e. the (composite) forcing $(\mathbf{Y})$ and precipitation $(\mathbf{X})$, were filtered to the intraseasonal scale between 20 and 100 days without lag.

\subsubsection{Amplitude and phase of the MITB index}

The MITB index was constructed based on adapting the following methods: (a) Mathews (2000), who worked using an EOF-based approach applied to OLR; (b) Wheeler and Hendon (2004), who used a multivariate EOF approach applied to OLR, U850, and U200; and (c) Lee et al. (2012), who applied the method in (b) to Asia. The MITB index uses an MCA-based approach, where the two first modes are kept (i.e. MCA1 and MCA2).

In this study, the following MCA expansion coefficients are used, $Z(t)=\left[M I T B_{1}, M I T B_{2}\right]$, where:

$$
\operatorname{MITB}_{1}=\left[\mathbf{a}_{1}, \mathbf{b}_{1}\right] \quad \operatorname{MITB}_{2}=\left[\mathbf{a}_{2}, \mathbf{b}_{2}\right]
$$

Table 1 Contingency table used to evaluate the association between $P R P_{e}$ and strong MITB events

\begin{tabular}{lll}
\hline$M I B T \geq 3.5$ & $P R P_{e}$ & \\
\cline { 2 - 3 } & EXTR & Not EXTR \\
\hline High $(\geq 3.5)$ & $\pi_{h}$ & $1-\pi_{h}$ \\
Low $(<3.5)$ & $\pi_{l}$ & $1-\pi_{l}$ \\
\hline
\end{tabular}

Also, the amplitude $(\|\mathbf{Z}\|)$ and phase $(\hat{\alpha})$ may be obtained from the $a_{1}$ and $b_{1}$ coefficients through the following equations:

$\|\mathbf{Z}\|(t)=\sqrt{\left(\frac{a_{1}+b_{1}}{2}\right)^{2}+\left(\frac{a_{2}+b_{2}}{2}\right)^{2}}$

$\hat{\alpha}(t)=\arctan \left(\frac{a_{2}(t)+b_{2}(t)}{a_{1}(t)+b_{1}(t)}\right)$

\subsection{Odds ratio}

The odds ratio (OR) was used to assess whether there is a connection between extreme values of the MITB index and extreme precipitation at each grid point and to measure the magnitude of this association. The results are displayed in a contingency table, as shown in Table 1. Extreme precipitation $\left(P R P_{e}\right.$, hereafter $)$ is determined as counts of values below (above) the 25th (75th) percentile that match intense MITB events with an amplitude larger than 3.5. This threshold refers to the amplitude of the MITB index selected through a two-sided Student's $t$-test. A value of 3.50 , or above, represents an amplitude that is statistically significant (at the $5 \%$ significance level).

Note that in Table $1, \pi$ is the probability of occurrence of $P R P_{e}$, and $\pi_{h}$ is the conditional probability of $P R P_{e}$ given the occurrence of strong MITB $\left(P[\pi \mid M I T B \geq 3.5]=\pi_{h}\right)$. Also, $\pi_{l}$ is the conditional probability of $P R P_{e}$ given the occurrence of weak MITB $\left(P[\pi \mid M I T B<3.5]=\pi_{l}\right)$. The ratio of the probability that the event occurs (i.e.: $\pi_{h}$ ) with respect to the probability that the event does not occur (i.e.: $1-\pi_{h}$ ) is called risk or odds (Stephenson 2000; Correia Filho et al. 2014), expressed by $\omega$ in the equations below:

$\omega_{h}=\frac{\pi_{h}}{1-\pi_{h}} \quad \omega_{l}=\frac{\pi_{l}}{1-\pi_{l}}$

And the ratio between them is given by:

$O R=\frac{\omega_{h}}{\omega_{l}}$

OR is interpreted as the ratio between the probabilities of an extreme precipitation event due to an extreme MITB event associated with its phase. If $O R<1$, then there is a 
Table 2 Contingency table used to evaluate the association between $P R P_{e}^{+}$and strong MITB events

\begin{tabular}{lll}
\hline$M$ & & \\
\cline { 2 - 3 } & EXTR $P_{t} \geq 3.5$ & Not EXTR \\
\hline High $(\geq 3.5)$ & $\pi_{h}$ & $1-\pi_{h}$ \\
Low $(<3.5)$ & $\pi_{l}$ & $1-\pi_{l}$ \\
\hline
\end{tabular}

$F$ represents the phase number (i.e.: $F=1,2 \ldots 7,8)$ and $i$ is the lag in days (i.e.: $i=0,1,2,3,4,5$ )

reduced probability of MITB-related extreme precipitation events. $O R>1$ may be described as a risk factor, i.e., there is a higher chance of having extreme precipitation events related to strong MIBT cases. $O R=1$ indicates that the chance of extreme rainfall events is independent of the MITB signal. A Chi-squared test was used to verify the statistically significance of the odds ratio values. Note that OR was calculated for each grid point.

The OR approach was also used to verify the relationship between the MITB phases, the MITB intensity, and the lagged positive rainfall extremes $\left(P R P_{e}^{+}\right.$, hereafter). Table 2 shows the contingency table plan used for the OR analysis.

\section{Results and discussion}

Figure 1 shows the seasonal variance of the OLR pattern. The global intraseasonal pattern from December to May is represented in Fig. 1a, which shows enhanced intraseasonal variance over the Indian Ocean, Oceania, and the West Pacific during the summer and austral fall (LinHo and Wang 2002; Lee et al. 2012). Figure 1c shows the intraseasonal
OLR pattern from June to November, showing a shift in the enhanced variance zones to a range between $10^{\circ} \mathrm{N}-20^{\circ} \mathrm{N}$ and is more concentrated in the north sector of the Indian Ocean and off the China coast. Also, there is a large contrast between the variance patterns in Latin America. Note that the variance is larger off the coast of Brazil (Fig. 1a) and then shifts towards Central America (Fig. 1d). These shifts may account for the changes in precipitation in $\mathrm{TBr}$ (Fig. 1d), and because of this, there is a major reduction in the precipitation pattern, which may impact the hydrological cycle in the Amazon and northeastern regions of Brazil (Marengo and Espinoza 2015; Marengo et al. 2013).

The results shown in Fig. 1 are also in agreement with previous studies (Souza and Cavalcanti 2009; Alvarez et al. 2014; Tomaziello et al. 2015), which show that the MJO is the main intraseasonal variability pattern at play in South America, during the austral summer and fall.

\subsection{The main MITB features}

Considering the strong relationship between the OLR pattern and precipitation in South America, these two variables are used with the zonal component of the wind at 200 and $850 \mathrm{hPa}$, i.e.: due to the baroclinic eastward propagation of the OLR pattern (Kessler et al. 1995; Gonzalez and Vera 2014; Kiladis et al. 2014), to construct the MITB index. The spatial structure of the MCA is shown in Fig. 2. The MCA modes 1 and 2 explain $85 \%$ of the variance. This value is quite high considering the level of variability of the input data, the seasonality, and the daily time scale. Note that the second mode of variability found here (MCA2) cannot be directly compared with other studies, since most studies do not explore the second mode of variability of
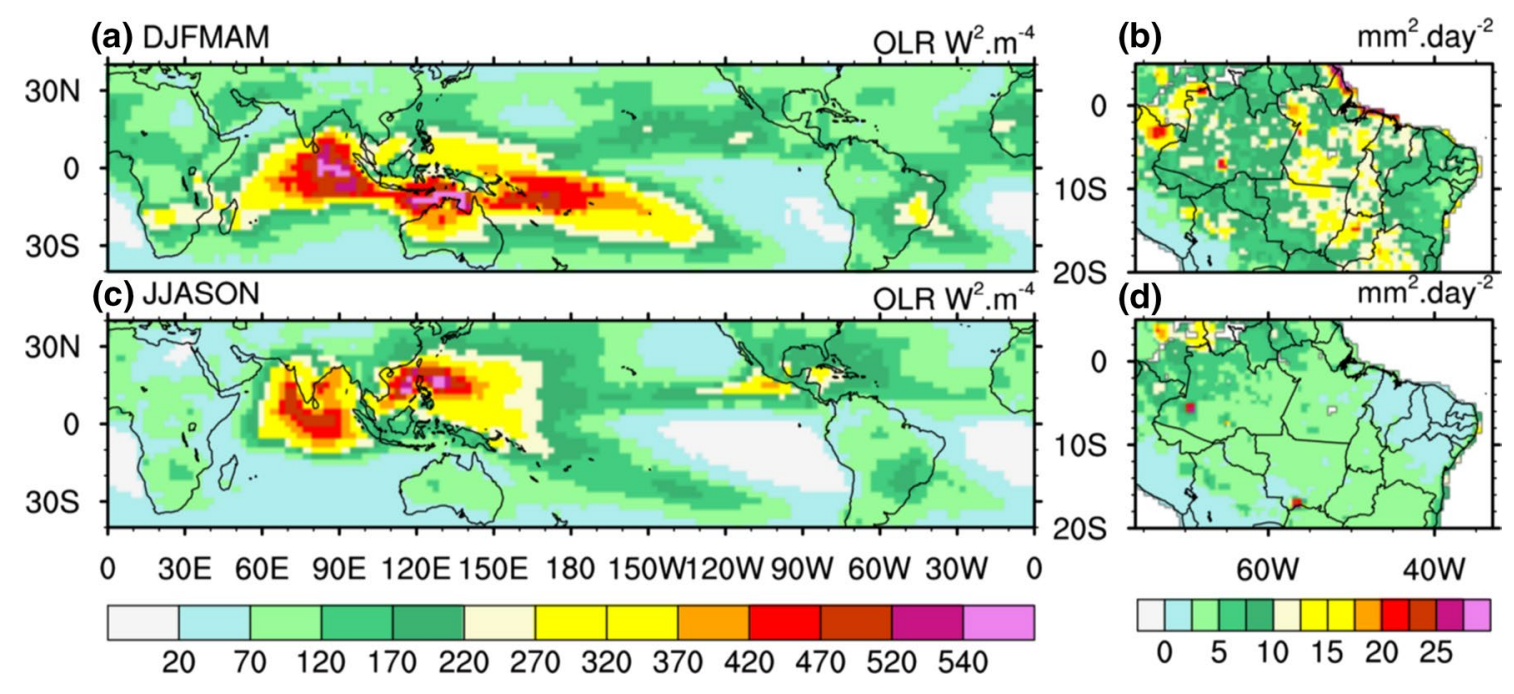

Fig. 1 Seasonal variance of OLR and precipitation filtered to the range of 20-100 days. a OLR for the period from December to May; b Precipitation from December to May; c OLR from June to November; d precipitation from June to November 


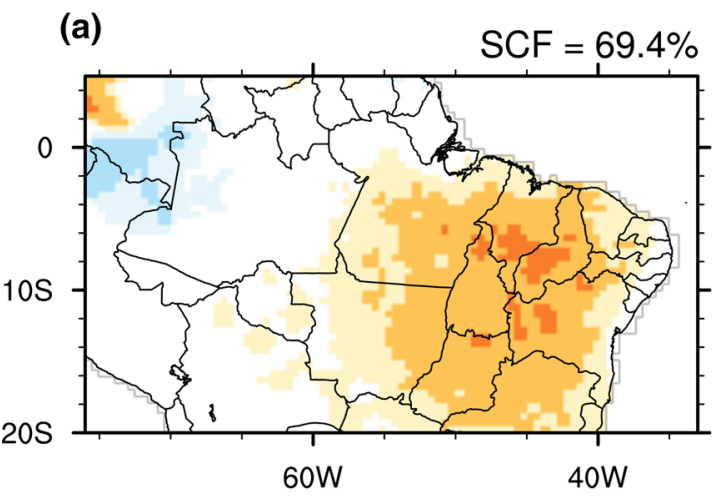

(c)

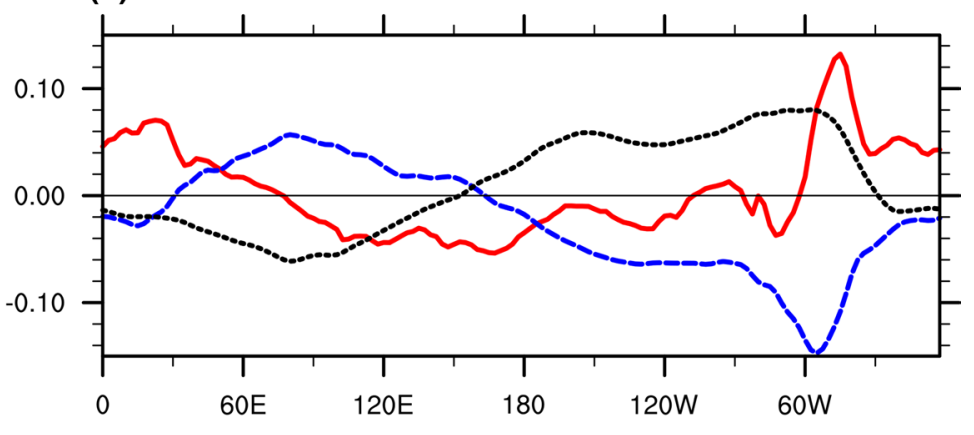

(b)

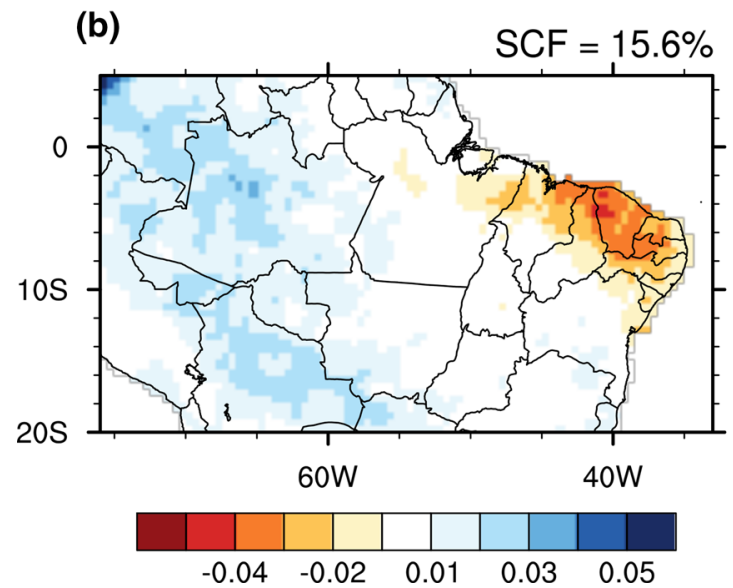

(d)

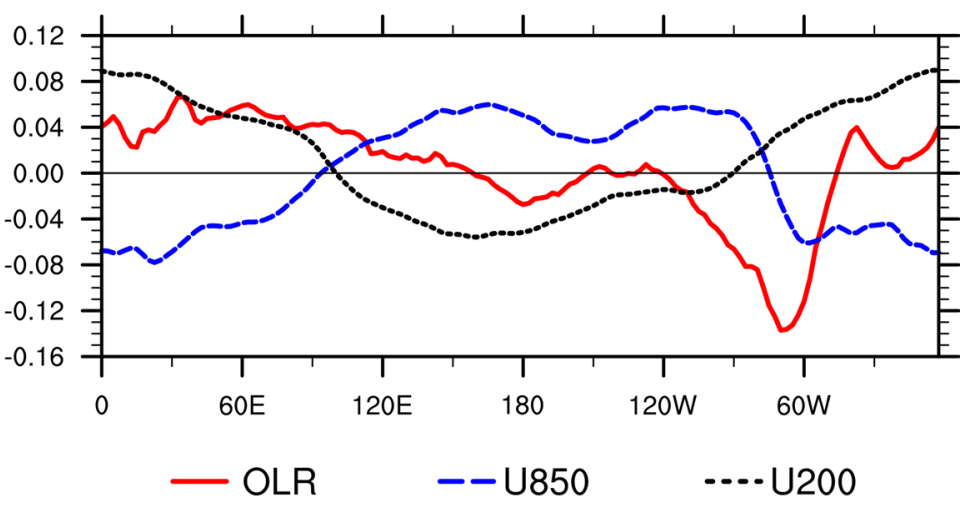

Fig. 2 Spatial structure of the MCA1 and MCA2 modes. a and b represent the singular precipitation values, $U_{1}$ and $U_{2}$, respectively; c and $\mathbf{d}$ are the singular values, $V_{1}$ and $V_{2}$, related to the dynamic variables (i.e.: U850, U200, and ORL), respectively

multivariate methods, such as the EOF approach (De Souza and Ambrizzi 2006; Muza et al. 2009; Silva and Carvalho 2007).

The spatial rainfall pattern related to the first MCA mode (MCA1), is consistent with the spatial configuration characterized by the EOF-based approach in De Souza and Ambrizzi (2006) and Jones and Carvalho (2013). Regardless of the precipitation anomaly (whether it is positive or negative), MCA1 reasonably captures the rainfall pattern of the largest part of the northeastern region in Brazil (NEB, hereafter), as well as the east and southeast sectors of the Amazon. There are also enhanced anomalies located on the northeast coast and the semi-arid regions in Brazil (Fig. 2a).

Furthermore, there is a marked dipole pattern between the northeastern (negative sign) and the western (positive sign) $\mathrm{TBr}$ sectors (Fig. 2b). The anomalous precipitation pattern over the northern and eastern part of NEB is heterogeneous, that is, the anomalies may not have the same sign throughout the region. This is different from the MCA1, where the pattern is homogeneous. This is also consistent with the composite analysis pattern of De Souza and Ambrizzi (2006), where the negative (positive) anomalies precede (succeed) the maximum intraseasonal extreme precipitation.

When it comes to the dynamic components of MCA1 (Fig. 2c) and MCA2 (Fig. 2d), the OLR maximum is found between $80^{\circ} \mathrm{W}$ and $20^{\circ} \mathrm{E}$, in the region that covers South America, the Atlantic Ocean and the west African coast. This maximum is linked with the strengthening of the easterly surface wind and of the high level westerlies. Note also an opposite OLR sign (of lower intensity) over the Indian Ocean, Oceania and east Pacific. So, the intensification (weakening) of the convection in South America and Africa is related to the weakening (intensification) over the Indian Ocean and Oceania (Fig. 2c).

Also, the negative OLR pattern shows negative and intense values in the western sector of South America, whereas the positive sign with lower intensity may be seen between $60^{\circ} \mathrm{W}$ and $40^{\circ} \mathrm{W}$ (Fig. 2d). These negative and positive patterns correspond to the influx of easterlies (westerlies) in lower (higher) levels over the Atlantic Ocean, Africa and eastern sector of the Indian Ocean. Note that Wheeler and Hendon (2004) and Ventrice et al. (2013) describe the overall propagation of the MJO signal through an EOF-based approach. Although their studies are not directly comparable 
Fig. 3 Spectral analysis of the MCA expansion coefficients. The diagram for a represents the temporal expansion coefficients $A 1$ and $A 2$ related to rainfall patterns; and b shows the temporal expansion coefficients $B 1$ and $B 2$ related to the dynamic variables (i.e.: U850, U200, and ORL)

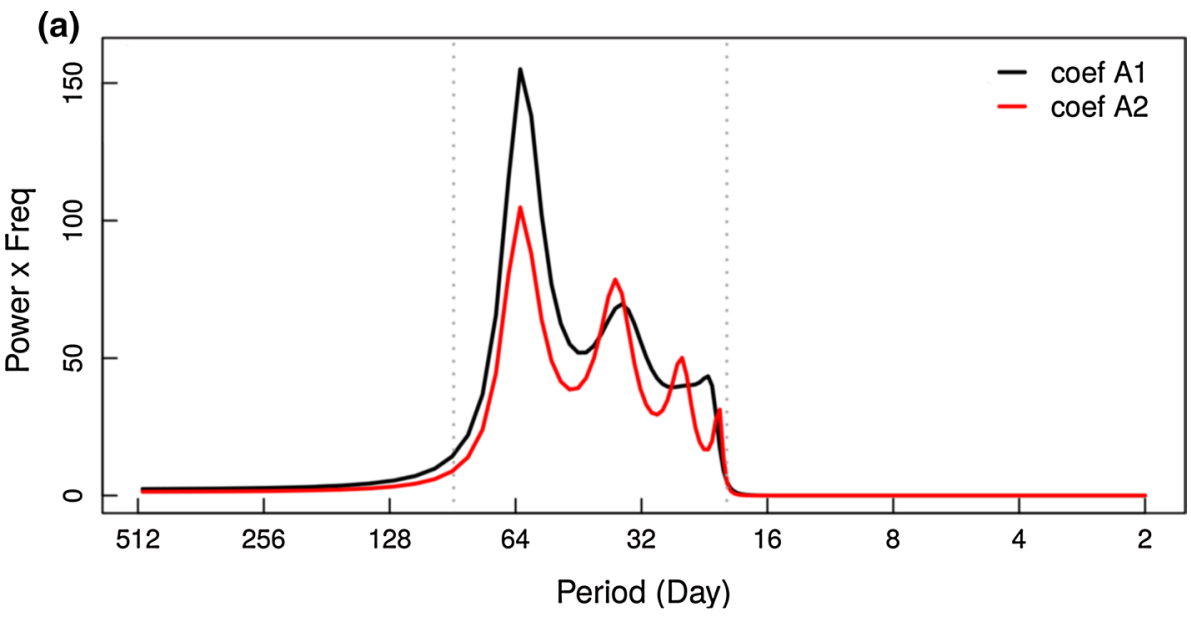

(b)

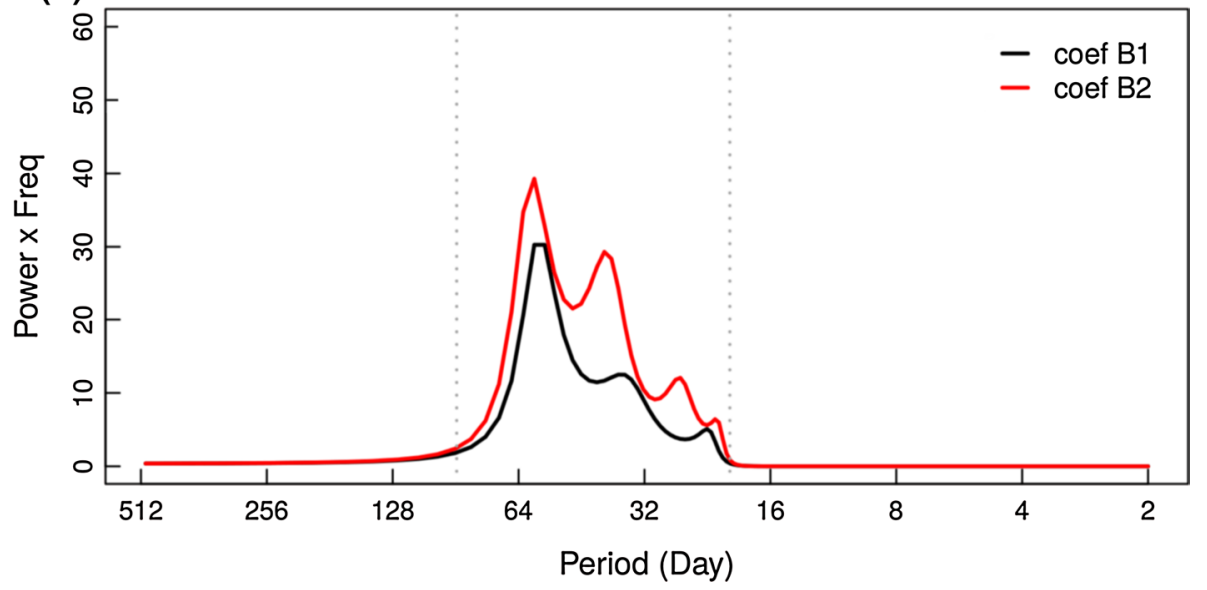

here, a qualitative comparison of the peak of their convective core with this study could provide insights into the regional propagation of the intrasesonal signal. The localization of their convective core is between $60^{\circ} \mathrm{E}$ and $120^{\circ} \mathrm{E}$ (i.e. over the Indian Ocean, Oceania, and the eastern Pacific). Here, the MITB index shows a peak over South America because it uses precipitation data over that region. So, the MITB pattern reflects the propagation of the signal observed in Wheeler and Hendon (2004) and Ventrice et al. (2013) as perceived over South America. Hence, this highlights that MITB is able to capture the location and shift of the intraseasonal oscillation that generates the TBr precipitation.

The MITB spatial pattern has been presented so far; but one still needs to verify whether the MCA1 and MCA2 time series are able to represent the intraseasonal scale appropriately. Figure 3 a shows the variance of the power spectrum of the $A 1$ and $A 2$ MCA coefficients (related to the precipitation variable). The variance of the power spectrum is concentrated in the intraseasonal period of 20-100 days. Also, the $A 1$ and $A 2$ coefficients are more sensitive to the intraseasonal signal compared with the $B$ coefficients. So, this indicates that the filtering process was arguably reasonable and that the MITB response is dominated by the intraseasonal signal of precipitation, especially taking into account standardized input variables (i.e. precipitation, OLR, U850, and U200) and that the temporal coefficients were standardized by the square root of their respective singular values $\left(\lambda_{1}\right.$ and $\left.\lambda_{2}\right)$. Furthermore, the $B 1$ and $B 2$ coefficients, related to the dynamic variables, have a lower magnitude compared with $A 1$ and $A 2$. However, the frequency captured by the $A$ and $B$ coefficients is still the same, i.e.: between 20 and 90 days (Fig. 3b).

Next, to understand the relationship between the intraseasonal and interannual frequencies and to identify the phase of this relationship, the cross spectrum of the $M I T B_{1}$ and $M I T B_{2}$ indices is evaluated in Fig. 4. It reveals peaks between 21 and 120 days (Fig. 4a), with mean squared coherence values of 0.44 (Fig. 4a lower panel). In Fig. 4a (upper panel), the phase analysis shows that $M I T B_{1}$ and $M I T B_{2}$ have a phase difference of $1 / 4$ of the cycle. Figure $4 \mathrm{~b}$ shows the cross correlation between $M I T B_{1}$ and $M I T B_{2}$. The phase relationship is negative, such that $M I T B_{1}$ is 10 days ahead of $M I T B_{2}$. The phase difference patterns are part of a propagating mode, and depending on the signal and the region of interest, MITB could potentially have a diagnostic use. 

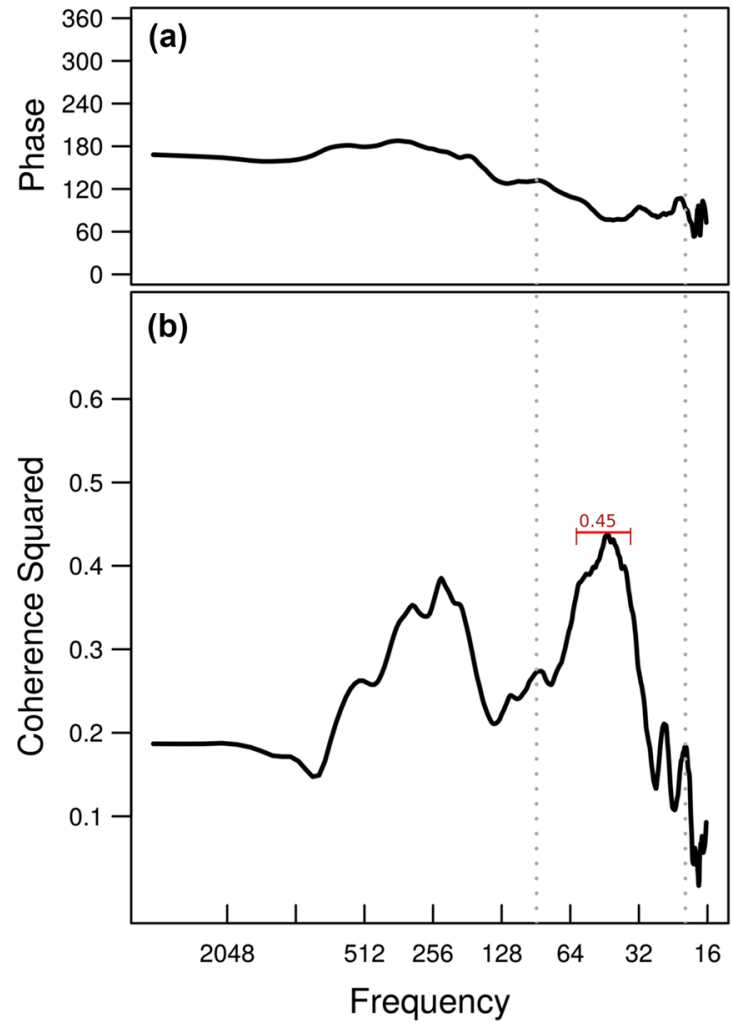

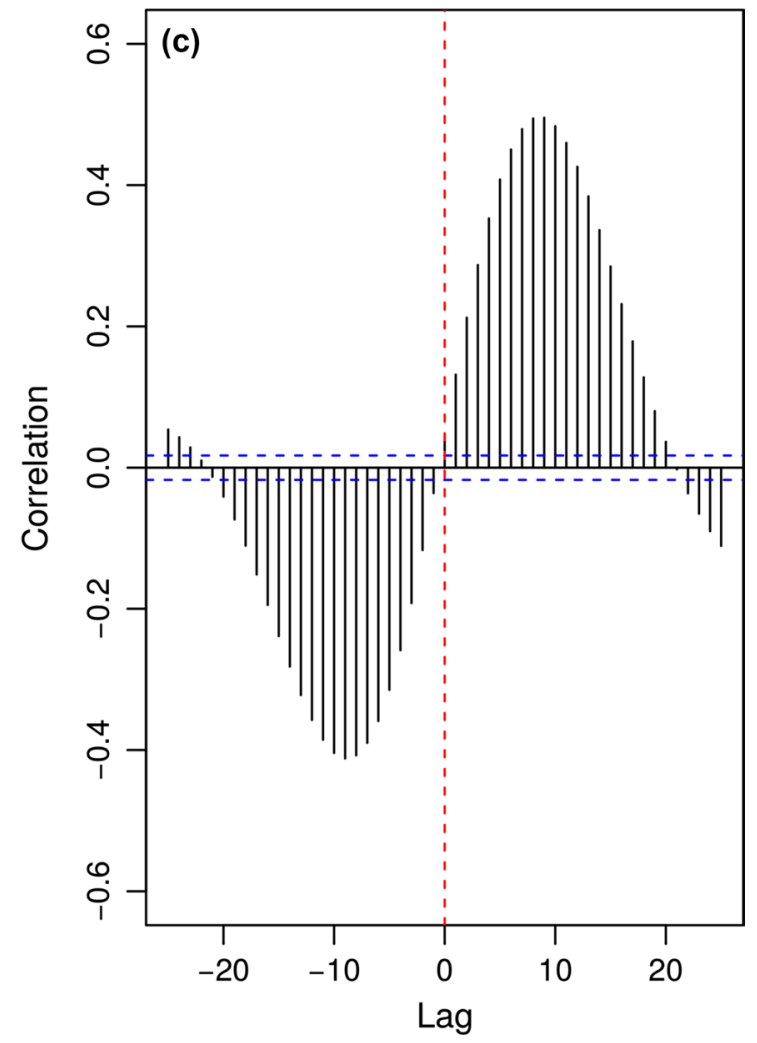

Fig. 4 a Spectral coherence analysis between the $M I T B_{1}$ and MIBT2. The panel in (a) represents the phase; $\mathbf{b}$ shows the squared coherence; and c displays the cross-correlation between $M I T B_{1}$ and $M I T B_{2}$

Table 3 Sensitivity analysis of different MCA inputs

\begin{tabular}{llll}
\hline Fields & $\begin{array}{l}\text { Squared covariance } \\
\text { fraction (\%) }\end{array}$ & $\begin{array}{l}\text { Fraction of Covariance } \\
\text { in the range of 20-100 days }\end{array}$ & $\begin{array}{l}\text { Average } \text { Ooh }^{2} \text { in the } \\
\text { range of 20-100 days }\end{array}$ \\
\hline OLR & 82 & 0.54 & 0.11 \\
OLR, U850 & 83 & 0.61 & 0.18 \\
OLR, U850, U200 & 85 & 0.65 & 0.27 \\
Average over $5^{\circ} \mathrm{S}-5^{\circ} \mathrm{N}^{\mathrm{a}}$ & 81 & 0.63 & 0.23 \\
Average over $25^{\circ} \mathrm{S}-25^{\circ} \mathrm{N}^{\mathrm{a}}$ & 83 & 0.63 & 0.21 \\
Maps over $5^{\circ} \mathrm{S}-5^{\circ} \mathrm{N}^{\mathrm{a}}$ & 78 & 0.70 & 0.34 \\
Maps over $15^{\circ} \mathrm{S}-15^{\circ} \mathrm{N}^{\mathrm{a}}$ & 75 & 0.76 & 0.42 \\
\hline
\end{tabular}

${ }^{\text {a }}$ OLR, U850 and U200

\subsection{Sensitivity analysis of the MCA approach}

Here, the sensitivity of the MCA to the following variables (and their combinations) is shown: (a) OLR; (b) OLR and U850; and (c) OLR, U850, and U200. Also, the sensitivity to the latitudinal bands is performed, to see whether a different choice of band would improve capturing the MJO signal. So, the bands $5^{\circ} \mathrm{S}-5^{\circ} \mathrm{N}$ and $25^{\circ} \mathrm{S}-25^{\circ} \mathrm{N}$ are tested, from which the meridional averages are calculated.

The meridional average results for the aforementioned variables and latitudinal bands are shown in the first five rows of Table 3. There, the proposed method of calculating the meridional averages of the latitudinal bands from $15^{\circ} \mathrm{S}$ to $15^{\circ} \mathrm{N}$ applied to the combined variables (i.e.: OLR, U850, and U200) gives the most appropriate result (shown in bold in Table 3).

Finally, the MCA method is applied to the spatial fields, as opposed to calculating meridional averages. The following bands of grid points are tested: (a) $5^{\circ} \mathrm{S}-5^{\circ} \mathrm{N}$; and (b) $15^{\circ} \mathrm{S}-15^{\circ} \mathrm{N}$. Note that the region from $25^{\circ} \mathrm{S}$ to $25^{\circ} \mathrm{N}$ is not tested due to the high computational cost of calculating a $4320 \times 4434$ maximum covariance matrix (i.e. 19,154,888 
values for the covariance matrix), which would counteract the objective of creating a method that captures the intraseasonal variability, which is computationally fast and feasible to calculate using a regular desktop computer. So, the results are presented in the last two rows of Table 3, showing that the average meridional values give a higher squared covariance fraction compared to working with grid points.

Hence, Table 3 confirms that the proposed combination of OLR, U850, and U200 for the meridional average from $15^{\circ} \mathrm{S}$ to $15^{\circ} \mathrm{N}$ has higher values of the squared covariance fraction. However, when it comes to the fraction of covariance and the average squared coherence $\left(\mathrm{Coh}^{2}\right)$, taking into account the spatial grid structure, higher values of covariance fraction (0.70 and 0.76) and Coh2 are seen (0.34 and 0.42 ) for the last two rows, respectively, as Table 3 shows. So, a choice had to be made for the selection of an appropriate model, and the principle of parsimony was used. It takes into account that: the meridional average is a simpler method and its computational cost is minimal. So, the chosen method is to work with the combination of the meridional average of OLR, U850, and U200 for its high squared covariance fraction and efficient computational cost. Also, this approach is in agreement with results found in Wheeler and Hendon (2004) and Ventrice et al. (2013).

In order to understand the structure and pattern of the variability captured by the MITB index, phase-space composites were constructed, similar to Wheeler and Hendon (2004) and Lee et al. (2012). Due to the enhanced out-of-phase characteristic between the $M I T B_{1}$ and $M I T B_{2}$, it is useful to diagnose the MITB state in a specific time through a phase-space diagram. So, Eqs. 6 and 7 are used, where the first determines the MITB amplitude and the second gives the angle between $M I T B_{2}$ and $M I T B_{1}$. For the phase-space diagram, events with an amplitude higher than 3.5 are selected, which is the miminum threshold so that the mean of the events is higher than the total mean (obtained through the use of a one-tailed Student's $t$-test with a $5 \%$ significance level).

Figure 5 shows the phase-space diagram curves related to composites of strong MITB events. The same approach given in Lee et al. (2012) is used, in which the diagram is divided into eight phases. Here, lags of 31 days were calculated for each phase. Also, note that the composite analysis is temporally dependent. One starts at lag -30 , which represents the first dot of each of the lines in Fig. 5. The first dot at phase 1 (blue line), for instance, is at lag -30 days; it starts in phase 1 and ends in phase 5 . The second dot is at lag -29 , the third is at lag -28 , and so on until the last dot (ending up in phase 5) at lag 0 . So, the phases have a sequential structure, which shows that MITB is able to represent the spatio-temporal evolution (i.e. propagation) of the intraseasonal signal. The phases with higher event frequency are phase numbers 1 and 8 , where the enhanced convective anomaly is over South America and Africa (see

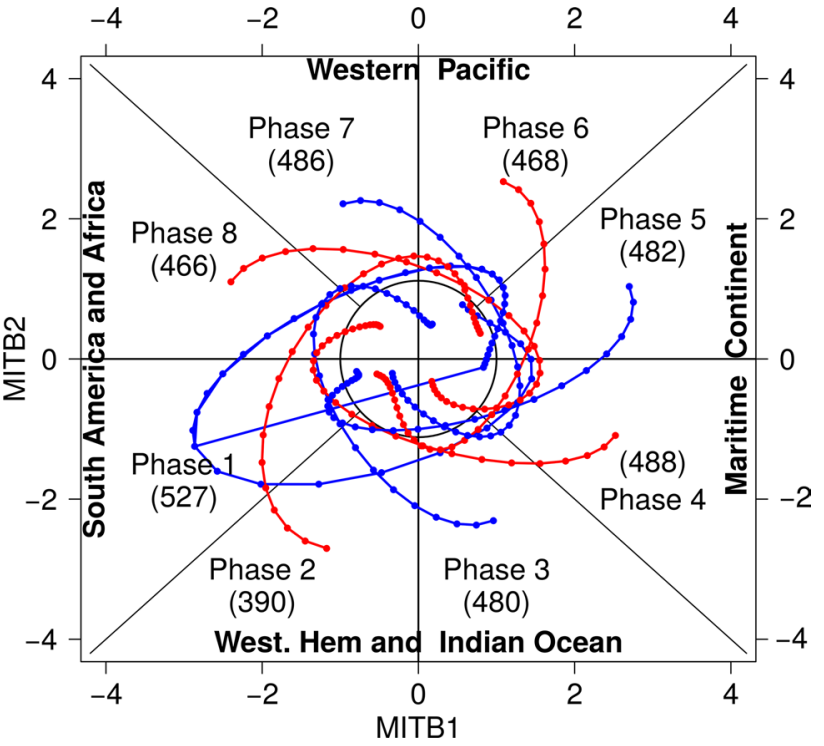

Fig. $5 M I T B_{1}$ and $M I T B_{2}$ phase-space compositions. Odd phases are represented in blue and even phases are shown in red. Each phase represents where the MITB amplitude exceeds 3.5. The number of events are shown in parentheses

Fig. 6). Also, the phases that are opposed (in sign) to those in 1 and 8 , are phase numbers 4 and 5, where the enhanced convective anomaly is found over the Indian Ocean and Oceania (see Fig. 6).

The spatial pattern of atmospheric variability explained by the MIBT index may be explored through the use of composite analysis. Fig. 6 provides the compositions for each of the eight stages shown in Fig. 5. The seasonal composition from December to May, depicts the structure and evolution of the MJO. In phase 1 (Fig. 6a, b), the core of weak convective activity is present in the central Pacific Ocean, while strengthening of convection is evident in Africa and the western Indian Ocean, related to the low level wind fields in western anomalies over the eastern Pacific, north of Oceania, and the Indian Ocean. In South America, convective activity is seen over the northeastern and southeastern regions, which enhances the positive signal of precipitation anomalies (Fig. 6b).

During subsequent phases, the convective core grows and moves eastward across the Indian Ocean, passing through northern Australia and leaning slightly to the southeast reaching approximately latitude $15^{\circ} \mathrm{S}$ over the western Pacific (Fig. 6 panel left). In South America, the center of convection weakened and shifted to the northeastern region (Fig. 6 panel right). From phases 3 through 5 , there is strong convective inhibition (i.e.: anticyclonic circulation), providing negative anomalies of intense rainfall over the largest part of TBr. These three propagation phases are in agreement with the negative rainfall anomaly response found in Muza et al. $(2006,2009)$. 

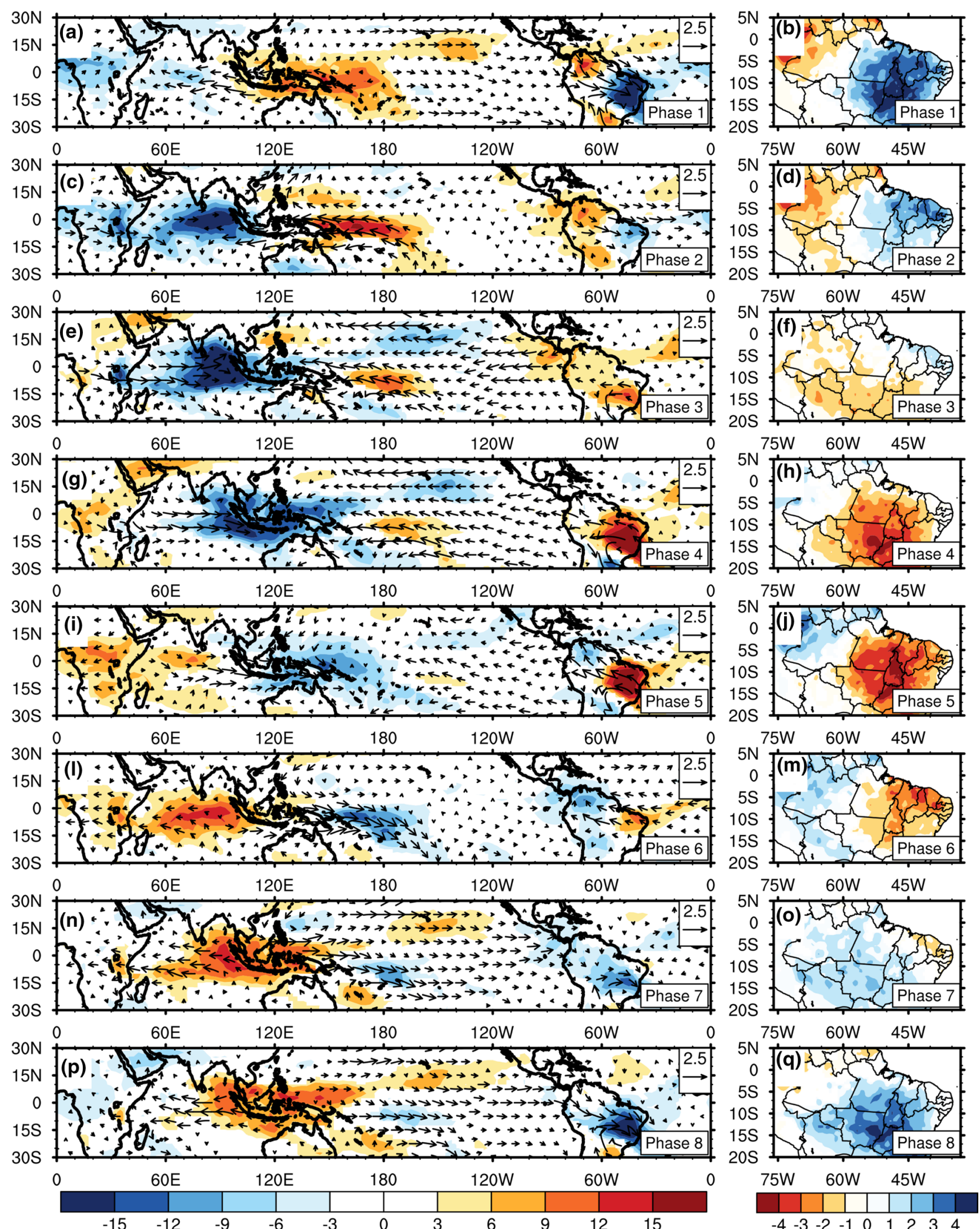

Fig. 6 Composite analysis. The panel on the left shows the life cycle of OLR anomalies (shaded) and winds at $850 \mathrm{hPa}$ (vectors); and the panel on the right shows the life cycle of rainfall (shaded) for the months from December to May. Only statistically significant values at the $5 \%$ significance level are shown 
In phases 2 and 6 , the spatial precipitation pattern is related to the MCA2 pattern (Fig. 2b). In phase 2, there are enhanced positive anomalies in northern NEB and eastern Amazon, and negative anomalies in the western end of the Amazon region. An enhanced convective band over tropical Atlantic and the Indian Ocean is linked with this phase (Fig. 6). In phase 6, however, there is an opposite spatial precipitation pattern: enhanced negative anomalies in northern NEB and eastern Amazon, and positive in the western end of the Amazon (Fig. 6). This phase is related to an inhibited band of convection over the tropical Atlantic and the Indian Ocean regions. According to Ventrice et al. (2013) and Barrett and Leslie (2009), this large-scale configuration corresponds to a strong MJO modulation of the frequency of hurricanes and cyclogenesis events over the tropical Atlantic Ocean.

\subsection{Odds ratio}

Here, the relationship between the occurrence of $P R P_{e}$ related to the MITB amplitude is discussed. Note that the threshold for extreme precipitation is represented as $(P R P e<25 p$ or $P R P e>75 p)$ [25p represents the 25th percentile and $75 \mathrm{p}$, the 75 th percentile]. These values are compared with the MITB amplitude with threshold at 3.5, according to Table 1. So, Fig. 7 shows the odds ratio per grid point, which characterises this relationship.

In Fig. 7, a statistically significant $O R>1$ spatial pattern is observed in the continental region of South America, within the tropical belt that extends in the direction of the region of influence of the ITCZ (north of NEB) and the SACZ (southeastern region of Brazil). There are no significant values over the east coast of NEB. Also, this region of $O R>1$ is influenced by the dynamic pattern of MITB, where the values from 1.5 to 3.5 correspond to relatively high odds ratio values. So, for example, the odds of having extreme precipitation events is 1.5 to 3.5 higher when the MITB index is strong (i.e. MITB with amplitude higher than 3.5) compared to a weak MITB index. Note that the latter 3.5 value refers to the amplitude of the MITB index, which was used for the strong/weak threshold. This means that for (roughly) every three extreme precipitation events, two are related to strong MITB events and one to a weak MITB event. In contrast, there are significant $O R<1$ values between 0.50 and 0.75 in the northern sector of the Amazon, covering the states of Roraima and Guyana, which indicate a higher chance of $P R P_{e}$ occurrence when MITB is weak, i.e. when the intraseasonal system performance is neutral or weak.

Next, the association between MITB and extreme precipitation events with respect to phases and lags are considered through a test of association between strong MITB events (i.e. amplitude above 3.5 for each phase, 1-8) and

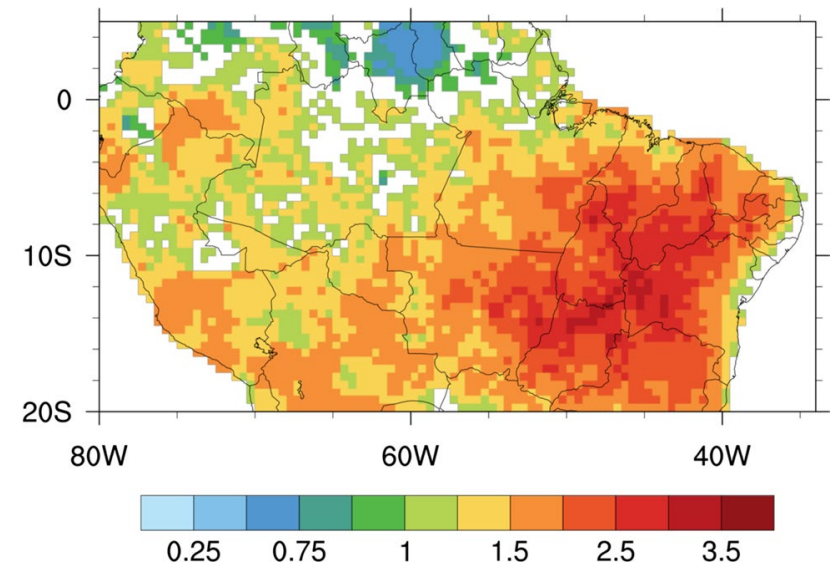

Fig. 7 Point map of the odds ratio values based on the contingency table used to test the association between the amplitude of the MITB index (threshold $=3.5$ ) and the occurrence of extreme precipitation $(P R P e<25 p$ or PRPe $>75 p)$ [25p is 25 th percentile and $75 p$ is the 75 th]. Only statistically significant results are shown (at the $5 \%$ significance level)

positive extreme precipitation events $\left(P R P_{e}^{+}\right.$for different lags, from 0 to 35 days, as shown in Fig. 8. For the spatial "Lag 0" pattern (Fig. 8, first column on the left), OR shows spatial similarity to each phase of the precipitation composites shown in Fig. 6. For regions with positive precipitation anomalies (Fig. 6), there are statistically significant $O R>1$ values (see Fig. 8). On the other hand, for regions where there are negative precipitation anomalies, there are statistically significant $O R<1$ values.

Also, phases 1, 2, 7, and 8 show mostly $O R>1$ values ranging from 3 to 9, particularly over eastern Amazon and NEB. Besides that, $O R<1$ values ranging from 0.15 and 0.75 are found over the western and northwestern sectors of the Amazon basin. Note that for phases 3, 4, 5, and 6, there is an inverted spatial pattern, that is, for regions where $O R<1$ (i.e.: NEB and east Amazon), there are $O R>1$ values over the western and northwestern parts of the Amazon basin.

Simply put, one can say that for each $P R P_{e}^{+}$event in phase 1 , where $O R<1$, there is a maximum of nine $P R P_{e}^{+}$ events taking place in other phases. However, for regions where $O R>1$, for every nine events in phase 1 , there is only one event in the other phases.

Moreover, two main features that should be mentioned in Fig 8 are: (a) there is a spatial feature of persistence of statistically significant $O R$ values between lag 0 and lag +7 (Fig. 8, second panel to the left); b) there is an inversion of $O R$ values between lags +7 and +14 . Then, the lag +14 pattern persists until lag +35 . This shows that MITB is able to capture the propagation of the intraseasonal signal, as assessed by the $O R$ analysis. Thus, MITB could potentially be used as a diagnostic and prognosis tool to study 


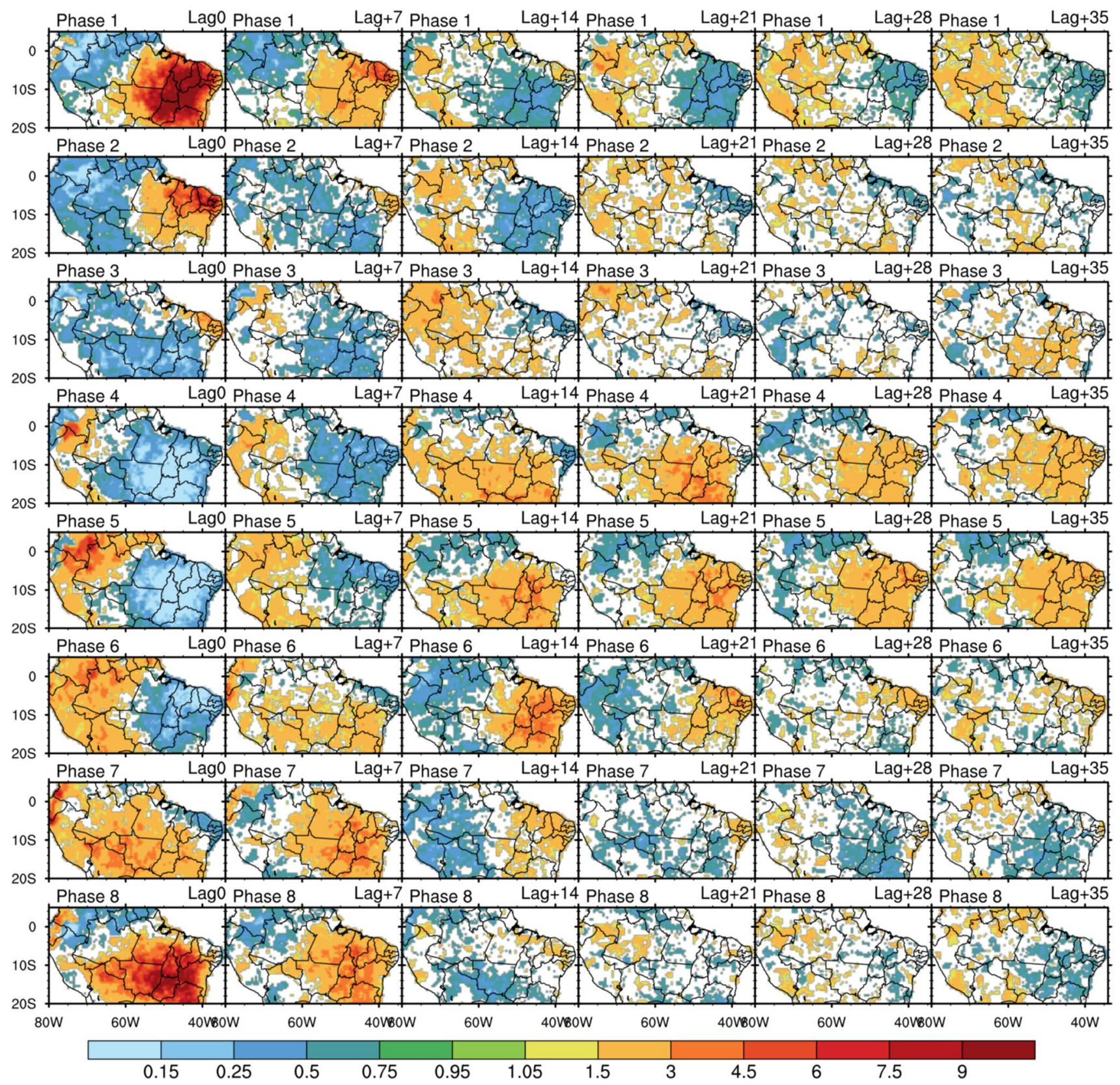

Fig. 8 Odds ratio between the extremes of precipitation and MITB considering the phase, amplitude and delay, were plotted only statistically significant at the level of $5 \%$

intraseasonal rainfall variability, because it captures precipitation events between 7 and 35 days.

\section{Conclusions}

The impact of the intraseasonal variability of precipitation over $\mathrm{TBr}$ was analysed through the development of the MITB index. This index has provided a consistent assessment on the time and intensity of the intraseasonal variability signal in the region. Also, it has given a new perspective for its use in monitoring and prognosis of convective activity related to the intraseasonal variability.

The MCA-based index was able to capture about $86 \%$ of the variability between the dynamic variables and the $\mathrm{TBr}$ precipitation. The first two modes MCA1 and MCA2 reasonably describe the intraseasonal signal propagation; this is true especially for MCA1, which shows a similar response to that found in other studies (De Souza and Ambrizzi 2006; Muza et al. 2009). Also, MITB 1 and 
$M I T B_{2}$, which were based on the first two MCA modes, show the highest correlation with a 10-day lag.

Also, a vectorial projection of $M I T B_{1}$ and $M I T B_{2}$ shows that phases $1,2,7$, and 8 are related to the ocurrence of positive precipitation anomalies, whereas phases 3-6 show the same, but for negative anomalies of precipitation for most of $\mathrm{TBr}$. For the maximum and minimum phases, that is, for the pair of phases $8-1$ and 5-6, respectively, there is an inverse relationship of the precipitation sign (i.e.: whether positive or negative) between the northwestern Amazon region and the region under the influence of ITCZ and SACZ.

The $O R$ analysis has shown an association between extreme precipitation events in tropical Brazil with strong MITB events. It also captured the temporal dependence of precipitation extremes with respect to both the phase and intensity of MITB. Significant values of $O R>1$ are observed mainly in the propagation of the convective signal from phases $7,8,1$, and 2 . This is true both for lags 0 and +7 . In phase 2 at lag +7 , however, the convective system starts dissipating and most of $\mathrm{TBr}$ has an $O R<1$ pattern. Then, there is a change in OR sign from lags +14 to +35 days, which confirms that MITB has a prognostic potential with respect to $P R P_{e}^{+}$, with at least 14 to 35 days before the occurrence of an extreme precipitation event. This is especially the case for phases 3-4 and 5-6.

In summary, to answer the scientific questions posed at the start, in this research work it has been found that: (a) the equatorial mean from $15^{\circ} \mathrm{N}$ to $15^{\circ} \mathrm{S}$, and the use of OLR, U850 and U200, were chosen because they were able to represent both the intraseasonal signal and its propagation, in addition to having a lower computational demand to elaborate the MITB index; and (b) MITB was able to capture the intraseasonal features over TBr. One of its main advantages is its ability to identify and reproduce extreme events related to the intraseasonal signal.

It is important to emphasize that the results as found in this paper reinforced the presence of atmospheric oscillations and their impact on precipitation over South America, mainly associated with extreme rainfall over TBr. Further work is underway to explore the relationship between the intraseasonal variability with the seasonal signal and interannual climatic events.

\begin{abstract}
Acknowledgments NJC Barreto and G.U. Pedra were supported by Fundao CAPES (PhD scholarschips CAPES-DS and CAPESREUNI), P.S. Lucio is sponsored by a PQ2 grant (Proc. 302493/20077) from CNPq (Brazil), and MdS Mesquita is funded through the Norwegian Research Council Grant Number 248803. We thank the two anonymous reviewers for their constructive comments to further improve the original manuscript.
\end{abstract}

Open Access This article is distributed under the terms of the Creative Commons Attribution 4.0 International License (http://creativecommons.org/licenses/by/4.0/), which permits unrestricted use, distribution, and reproduction in any medium, provided you give appropriate credit to the original author(s) and the source, provide a link to the Creative Commons license, and indicate if changes were made.

\section{References}

Alvarez MS, Vera C, Kiladis G, Liebmann B (2014) Intraseasonal variability in south america during the cold season. Clim Dyn 42(11-12):3253-3269

Alvarez MS, Vera CS, Kiladis GN, Liebmann B (2015) Influence of the Madden Julian Oscillation on precipitation and surface air temperature in South America. Clim Dyn 46(1-2): 245-262

Alves JMB, De Souza EB, Araújo A, Costa E, Da Silva M (2012) Sobre o Sinal de um Downscaling Dinâmico às Oscilações Intrassazonais de Precipitação no Setor Norte do Nordente do Brasil. Rev Brasil Meteorol 27(2):219-228

Barnett T (1991) The interaction of multiple time scales in the tropical climate system. J Climate 4(3):269-285

Barrett BS, Leslie LM (2009) Links between tropical cyclone activity and maddenjulian oscillation phase in the North Atlantic and Northeast Pacific Basins. Monthly Weather Rev 137(2):727-744. doi:10.1175/2008MWR2602.1

Carvalho LM, Jones C, Liebmann B (2004) The south atlantic convergence zone: Intensity, form, persistence, and relationships with intraseasonal to interannual activity and extreme rainfall. J Climate 17(1):88-108

Carvalho LMV, Jones C, Ambrizzi T (2005) Opposite phases of the Antarctic oscillation and relationships with intraseasonal to interannual activity in the tropics during the Austral summer. $\mathrm{J}$ Climate 18:702-718

Chen M, Shi W, Xie P, Silva VBS, Kousky VE, Higgins RW, Janowiak JE (2008) Assessing objective techniques for gauge-based analyses of global daily precipitation. J Geophys Res 113(D4):D04110. doi:10.1029/2007JD009132

Correia Filho WLF, Lucio PS, Spyrides MHC (2014) Precipitation extremes analysis over the Brazilian Northeast via logistic regression. Atmos Clim Sci (4):53-59

De Souza EB, Ambrizzi T (2006) Modulation of the intraseasonal rainfall over tropical brazil by the Madden-Julian oscillation. Int J Climatol 26(13):1759-1776

Duchon CE (1979) Lanczos filtering in one and two dimensions. J Appl Meteorol 18(8):1016-1022

Frankignoul C, Chouaib N, Liu Z (2011) Estimating the observed atmospheric response to SST anomalies: maximum covariance analysis, generalized equilibrium feedback assessment, and maximum response estimation. J Climate 24(10):2523-2539. doi:10. 1175/2010JCLI3696.1

Garreaud R, Aceituno P (2001) Interannual rainfall variability over the south american altiplano. J Climate 14(12):2779-2789

Gonzalez PL, Vera CS (2014) Summer precipitation variability over south america on long and short intraseasonal timescales. Climate Dyn 43(7-8): 1993-2007

Gonzalez PLM, Vera CS (2013) Summer precipitation variability over South America on long and short intraseasonal timescales. Climate Dyn. doi:10.1007/s00382-013-2023-2

Grimm AM, Silva Dias PL (1995) Analysis of tropical-extratropical interactions with influence functions of a barotropic model. J Atmos Sci 52(20):3538-3555

Grimm AM, Zilli MT (2009) Interannual variability and seasonal evolution of summer monsoon rainfall in South America. J Climate 22(9):2257-2275. doi:10.1175/2008JCLI2345.1

Hendon HH, Salby ML (1994) The life cycle of the Madden-Julian oscillation. J Atmos Sci 51(15):2225-2237

Inness PM, Slingo JM (2006) The interaction of the Madden-Julian oscillation with the maritime continent in a $\mathrm{gcm}$. Q J R Meteorol Soc 132(618): 1645-1667

Jones C, Carvalho LM (2002) Active and break phases in the south american monsoon system. J Climate 15(8):905-914 
Jones C, Carvalho LMV (2009) Stochastic simulations of the MaddenJulian oscillation activity. Climate Dyn 36(1-2):229-246. doi:10.1007/s00382-009-0660-2

Jones C, Carvalho LMV (2013) Climate change in the South American monsoon system: present climate and CMIP5 projections. J Climate 26(2013):6660-6679. doi:10.1175/JCL1-D-12-00412.1

Jones C, Carvalho LMV, Wayne Higgins R, Waliser DE, Schemm JKE, Barbara S, Sciences A, Atmospheres P, Brook S (2004) Climatology of tropical intraseasonal convective anomalies: 19792002. J Climate 17(3):523-539. doi:10.1175/1520-0442(2004)017<0523:COTICA>2.0.CO;2

Kalnay E, Kanamitsu M, Kistler R, Collins W, Deaven D, Gandin L, Iredell M, Saha S, White G, Joseph D (1996) The NCEP/NCAR 40-year reanalysis project. Bull Am Meteorol Soc 77(3):437-471

Kayano MT, Kousky VE (2006) Tropical circulation variability with emphasis on interannual and intraseasonal time scale. Rev Brasil Meteorol 11(17): 1996

Kessler WS, McPhaden MJ, Weickmann KM (1995) Forcing of intraseasonal kelvin waves in the equatorial pacific. J Geophys Res Oceans 100(C6): 10,613-10,631

Kiladis GN, Dias J, Straub KH, Wheeler MC, Tulich SN, Kikuchi K, Weickmann KM, Ventrice MJ (2014) A comparison of olr and circulation-based indices for tracking the mjo. Monthly Weather Rev 142(5):1697-1715

Knutson TR, Weickmann KM (1987) 30-60 Day atmospheric oscillations: composite life cycles of convection and circulation anomalies. Monthly Weather Rev 115(7):1407-1436

Kodama YM, Sagawa T, Ishida S, Yoshikane T (2012) Roles of the Brazilian Plateau in the Formation of the SACZ. J Climate 25(5):1745-1758. doi:10.1175/2011JCLI3785.1

Lee JY, Wang B, Wheeler MC, Fu X, Waliser DE, Kang IS (2012) Real-time multivariate indices for the boreal summer intraseasonal oscillation over the Asian summer monsoon region. Climate Dyn 40(1-2):493-509. doi:10.1007/s00382-012-1544-4

Levine RC, Turner AG, Marathayil D, Martin GM (2013) The role of northern Arabian Sea surface temperature biases in CMIP5 model simulations and future projections of Indian summer monsoon rainfall. Climate Dyn 1-18. doi:10.1007/ s00382-012-1656-x

Liebmann B, Smith C (1996) Description of a complete (interpolated) outgoing longwave radiation dataset. Bull Am Meteorol Soc 77(6): 1275-1277

Liebmann B, Kiladis GN, Vera CS, Saulo AC, Carvalho LM (2004) Subseasonal variations of rainfall in south america in the vicinity of the low-level jet east of the andes and comparison to those in the south atlantic convergence zone. J Climate 17(19):3829-3842

LinHo, Wang B (2002) The time-space structure of the asianpacific summer monsoon: a fast annual cycle view*. J Climate 15(15):2001-2019

Madden RA, Julian PR (1971) Detection of a 40-50 day oscillation in the zonal wind in the tropical Pacific. J Atmos Sci 28(5):702-708

Madden RA, Julian PR (1972) Description of global-scale circulation cells in the tropics with a $40-50$ day period. J Atmos Sci 29(6):1109-1123

Madden RA, Julian PR (1994) Observations of the 40-50-day tropical oscillation-a review. Monthly Weather Rev 122(5):814-837

Maharaj EA, Wheeler MC (2005) Forecasting an index of the madden-oscillation. Int J Climatol 25(12):1611-1618

Maloney ED, Hartmann DL (2000) Modulation of hurricane activity in the gulf of mexico by the Madden-Julian Oscillation. Science 287(5460):2002-2004

Maloney ED, Hartmann DL (2001) The madden-julian oscillation, barotropic dynamics, and north pacific tropical cyclone formation. part i: Observations. J Atmos Sci 58(17):2545-2558

Marengo J, Espinoza J (2015) Extreme seasonal droughts and floods in amazonia: causes, trends and impacts. Int J Climatol
Marengo JA, Alves LM, Soares WR, Rodriguez DA, Camargo H, Riveros MP, Pabló AD (2013) Two contrasting severe seasonal extremes in tropical South America in 2012: flood in amazonia and drought in northeast Brazil. J Climate 26(22):9137-9154

Mathews AJ (2000) Propagation mechanism for the Madden-Julion oscillation. Q J R Meteorol Soc 126:2637-2652

Mo R (2003) Efficient algorithms for maximum covariance analysis of datasets with many variables and fewer realizations: a revisit. J Atmos Ocean Technol 20(3):1804-1809

Muza MN, de Carvalho LMV, Carvalho LMV (2006) Variabilidade intrasazonal e interanual de extremos na precipitaÇÃo sobre o centro-sul da amazÔnia durante o verÃo australf. Rev Brasil Meteorol 21(3):29-41

Muza MN, Carvalho LM, Jones C, Liebmann B (2009) Intraseasonal and interannual variability of extreme dry and wet events over southeastern south america and the subtropical atlantic during austral summer. J Climate 22(7):1682-1699

Navarra A, Simoncini V (2010) Generalizations: rotated, complex, extended and combined eof. A guide to empirical orthogonal functions for climate data analysis. Springer, New York

Paegle JN, Byerle LA, Mo KC (2000) Intraseasonal modulation of south american summer precipitation. Monthly Weather Rev 128(1983):837-850

Robledo FA, Penalba OC, Bettolli ML (2013) Teleconnections between tropical-extratropical oceans and the daily intensity of extreme rainfall over argentina. Int J Climatol 33(3):735-745

Silva AE, Carvalho LMV (2007) Large-scale index for South America Monsoon (LISAM). Atmos Sci Lett 8(May):51-57. doi:10.1002/ asl

Souza P, Cavalcanti IFA et al (2009) Atmospheric centres of action associated with the atlantic itcz position. Int $\mathrm{J}$ Climatol 29(14):2091

Stephenson DB (2000) Use of the odds ratio for diagnosing forecast skill. Weather and Forecast 15(2):221-232

Todd MC, Washington R, James T (2003) Characteristics of summertime daily rainfall variability over South America and the South Atlantic convergence zone. Meteorol Atmos Phys 83(1-2):89108. doi:10.1007/s00703-002-0563-9

Tomaziello ACN, Carvalho LM, Gandu AW (2015) Intraseasonal variability of the atlantic intertropical convergence zone during austral summer and winter. Clim Dyn 47(5-6):1717-1733

Valadão CE, Lucio PS, Chaves RR, Carvalho LM (2015) Mjo modulation of station rainfall in the semiarid seridó, northeast brazil. Atmos Climate Sci 5(04):408

Ventrice MJ, Wheeler MC, Hendon HH, Schreck CJ, Thorncroft CD, Kiladis GN (2013) A modified multivariate maddenjulian oscillation index using velocity potential. Monthly Weather Rev 141(12):4197-4210. doi:10.1175/MWR-D-12-00327.1

Vitorino MI, da Silva Dias PL, Ferreira NJ (2006) Observational study of the seasonality of the submonthly and intraseasonal signal over the tropics. Meteorol Atmos Phys 93(1):17-35

Weickmann KM (1983) Intraseasonal circulation and out going longwave radiation modes during northern hemisphere winter. Monthly Weather Rev 111(9):1838-1858

Wheeler MC, Hendon HH (2004) An all-season real-time multivariate MJO index: development of an index for monitoring and prediction. Monthly Weather Rev 132(8):1917-1932. doi:10.1175/1520-0493(2004)132<1917:AARMMI>2.0.CO;2

Wilks DS (2015) Multivariate ensemble model output statistics using empirical copulas. Q J R Meteorol Soc 141(688):945-952

Wu MLC, Schubert S, Huang NE (1999) The development of the south asian summer monsoon and the intraseasonal oscillation. $\mathrm{J}$ Climate 12(7):2054-2075

Zhang C, Dong M (2004) Seasonality in the MaddenJulian oscillation. J Climate 17(16):3169-3180. doi:10.1175/1520-04 42(2004)017<3169:SITMO>2.0.CO;2 